\title{
ПЕРЕВОДЧЕСКИЙ ТРАНСФЕР ПРОКСЕМНОЙ ТЕКСТОВОЙ МОДЕЛИ (НА МАТЕРИАЛЕ ПРОИЗВЕДЕНИЯ У. ЧЕРЧИЛЛЯ «THЕ RIVER WAR»)
}

\author{
Е. А. Огнева \\ Белгородский государственный национальный исследовательский университет
}

\section{TRANSLATION TRANSFER OF PROXEMIC TEXT MODEL (IN W. CHURCHILL'S “THE RIVER WAR”)}

\author{
E. A. Ogneva \\ Belgorod State National Research University
}

\begin{abstract}
Аннотация: в статье рассматриваются текстовые модели, параметры которых обусловлены интенцией писателя, его идиостилем и сюжетно-тематическим построением текста. Целью исследования является установление тенденџии переводческого трансфера проксемных текстовых моделей как форматов авторского знания. Предметом исследования является структура проксемных моделей в оригинальном и переведенном текстах произведения У. Черчилля «The River War». В статье предпринята попытка классификации текстовых моделей, состоящих из четырех типов моделей: культурно-маркированной текстовой модели, темпоральной текстовой модели, проксемной текстовой модели, эмотивной текстовой модели. Обосновывается, что перечисленные типы моделей составляют сюжетно-тематическую текстовую модель. Констатируется тот факт, что проксемные текстовые модели представляют собой совокупность таких четырех типов проксем, как слова и словосочетания, семантика которых отражает пространство, глаголы движения, топонимы, пейзажные единицы как номинанты, описывающие в художественном тексте пейзаж. Анализируются проксемные текстовые модели в аспекте переводоведения и обосновываются отличия переводческого трансфера текстовых моделей от перевода текста как такового. Выявляется степень трансформации параметров проксемной текстовой модели произведения У. Черчилля «The River War» в результате ее переводческого трансфера из англоязычного текстового мира в русскоязычный текстовый мир. Интерпретируется симметричная/асимметричная передача параметров двух доминантных проксемных текстовых моделей, выявленных в произведении У. Черчилля «The River War»: проксемной текстовой модели «Египетский Судан», проксемной текстовой модели «Хартум» с английского языка на русский язык. Выявляется преобладание асимметричной передачи параметров двух доминантных проксемных текстовых моделей в результате переводческого трансфера.
\end{abstract}

Ключевые слова: перевод, переводческий трансфер, переводческие трансформации, текст, проксемная текстовая модель, моделирование, классификация проксем, проксема.

\begin{abstract}
These models have the parameters which are due to the writer's intensity, his idiostyle and the plot-thematic construction of the text. The aim of the study is to establish the tendencies of translation transfer of proxemic text models as the formats of author's knowledge. The subject of the study is the structure of proxemic models in the original and translated texts of W. Churchill's "The River War". The article attempted to classify of text, consisting of four types of models: a cultural-marked text model, a temporal text model, a proxemic text model, and an emotive text model. It is justified that the listed types of models constitute a plot-thematic text model. It is stated that proxemic text models are a combination of such four types of proxemes as: words and phrases, the semantics of which reflect space, verbs of movement, place names, landscape units as the nominantes representing the landscape in the literary text. Proxemic text models are analysed in the aspect of translation science and the differences between the translation transfer of text models and the translation of text as such are substantiated. The degree of transformation of the parameters of the proxemic text
\end{abstract}

(C) Огнева Е. А., 2021 
model of W. Churchill's "The River War" as a result of its translation from the English text world to the Russian text world is revealed. The symmetric/asymmetric transcoding of the parameters of two dominant proxemic text models of W. Churchill's "The River War" is interpreted from English to Russian such as the proxemic text model named as "Egyptian Sudan", and the proxemic text model named as "Khartoum". The predominance of asymmetric transcoding of the parameters of two dominant proxemic text models is identified as the translation transfer.

Key words: translation, translation transfer, translation transformations, text, proxemic text model, modeling, classification of proxemes, proxeme.

\section{Введение}

В современном языкознании одним из актуальных направлений развития научной мысли стало моделирование, в частности моделирование текста, предоставляющее спектр интерпретативных возможностей проникновения в текстовую материю. Под моделированием в этом случае следует понимать «целостную деятельностную программу, включающую последовательно примененный набор методов и приемов, направленных на системное представление какой-либо предметной области объекта (или предметов объекта) для получения информации об этом предмете, которую нельзя выявить в случае описательного подхода» [1, с. 95]. Описательный подход, как известно, был актуален в период становления теории текста, когда «на ранних этапах лингвистики текста, аналогичных другим дисциплинам лингвистики, существовало разделение на семантику текста, синтаксис текста, прагматику текста» [2, с. 25].

В отличие от описательного подхода к изучению текста, который основан на рассмотрении текстовой категориальности, при моделировании текста привлекается спектр интерпретативных приемов, создающих комплексную интерпретативную картину построения и функционирования того или иного текстового формата знания. Результат проникновения в материю текста в первом и во втором случае зависит от описания текста с позиций традиционных или синергетических, при условии, что «синергия текста» [3] выводит «понимание сложности на уровень самостоятельной науки, это описание сохраняет свою релевантность в силу многочисленности и многообразия текстовых измерений, именуемых признаками, аспектами, слоями» [4, с. 188].

Одним из компонентов текстовых измерений видится текстовое пространство, репрезентированное совокупностью проксем. Под проксемой понимается слово или словосочетание, семантика которого передает пространственный параметр. Рассмотрение текстового пространства позволяет представить его в виде модели. Под проксемной моделью понимается текстовый исследовательский конструкт, имеющий ядерно-периферийную структуру и состоящий из всех номинаций текстового пространства. В качестве ядра проксемной модели предстает слово, реже словосочетание, номинирующее модель текстового простран- ства. Периферию текстовой проксемной модели составляют все проксемы исследуемого текста.

Многообразие текстовых измерений обусловлено интенцией писателя, его идиостилем и сюжетно-тематическими параметрами вне зависимости от изображаемого в тексте мира, реального или вымышленного. Тем не менее в случае изображения реального мира «пространство произведения, или литературы в целом, или искусства нуждается в дистанцировании от мира» [5, p. 123]. Это дистанцирование достигается тем, что параметры текстовой модели отличаются от модели мира как такового.

Рассмотрение художественного текста в виде модели приводит к тому, что, по мнению зарубежных ученых, становится возможным установление того факта, что «the literary text model's transformation degree can be identified at the comparative process» $[6$, p. 23] / «степень трансформации модели художественного текста может быть идентифицирована посредством сопоставительного (компаративного) процесса» (здесь и далее перевод наш. - O. E.). В свете этого С. Костер подчеркивает, что сопоставительный процесс видится как «the part of literary translation process» [7, p. 142] / «часть процесса литературного перевода». В отечественном языкознании подчеркивается, что сопоставительные исследования «позволяют выявить специфику национального мировосприятия» [8, с. 52-53]. Взгляды С. Костера и Л. В. Борисовой на роль сопоставительных исследований коррелируют, поскольку значимая часть текстов, подвергаемых переводу, национально маркирована в той или иной степени.

Исследование текстовой модели оригинала как компонента компаративного процесса, который представляет собой часть процесса художественного перевода, выводит исследователей на новый уровень интерпретации результатов художественного перевода, основанного на знаковой природе двух типов текстовых единиц, культурно-маркированных и нейтральных, которые в совокупности создают единую текстовую модель, где «важнейшей характеристикой слова как лингвистического феномена является соотнесенность с объектом окружающего мира» [9, с. 563]. В этом случае объект окружающего мира становится объектом художественного мира, создаваемого писателем. При переводе художественный 
мир текста в той или иной степени трансформируется под воздействием модели мира, существующей в сознании переводчика, поэтому К. Скотт отмечает: «the literary translation is the replacing of author's world conception by translator's world conception» $[10$, p. 156] / «художественный перевод - это замещение концепции авторского мира концепцией мира переводчика», т. е., по мнению ученого, художественный перевод - это процесс «text transcoding and text perception» [11, p. 76] / «текстового перекодирования и текстового восприятия», где восприятие - это первая ступень к замещению одного мира другим, а перекодирование представляет собой процесс передачи структурно-семантического кода текста оригинала средствами языка перевода.

\section{Методы}

Методы, применяемые в исследовании, обусловлены целью проводимого научного изыскания по выявлению параметров переводческого трансфера проксемной текстовой модели. Применяемые методы представляют собой сопряжение сравнительно-сопоставительного анализа текста, компонентного анализа номинантов проксемной текстовой модели и приемов текстового таксономического моделирования. В качестве материала для исследования взяты тексты произведения У. Черчилля «The River War» / «Война на реке» на английском и русском языках.

\section{Основная часть}

Сюжетно-тематическая текстовая модель оригинала представляет собой совокупность следующих четырех текстовых моделей: 1) культурно-маркированная текстовая модель; 2) темпоральная текстовая модель; 3) проксемная текстовая модель; 4) эмотивная текстовая модель. Преобладающий тип модели по частотности ее номинантов в том или ином тексте предопределен сюжетом текста, который задается на основе интенции автора.

Исследование текстов показывает, что в каждой из перечисленных текстовых моделей можно выявить «рельефные сегменты <..>, которые характеризуются повышенной степенью смысловой значимости на соответствующем участке текста, особым филигранным лингвостилистическим оформлением и семантико-стилистическим отличием от ближнего левого и правого контекстов» [12, с. 18]. Рельефные сегменты призваны произвести на читателя значительное воздействие, т. е. нацелены на концентрацию внимания читателя, что способствует формированию их особого статуса в текстовой модели мира.

В модели текста как основного компонента текстового мира значимы «средства пространственной и временной референции эгоцентрических элементов» $[13$, с. 80$]$. Если сопрячь концепцию Р. Р. Чай- ковского о рельефных сегментах текста и концепцию Л. В. Комуцци и И. С. Гончаровой об эгоцентрических элементах текста, то очевидно, что эгоцентрические элементы текста представляют собой ядерные компоненты рельефных сегментов текста, которые, как было выявлено, вызывают наибольшие сложности при переводе, рассматриваемом как «языковой механизм и дискурсивная практика (процесс) трансфера текстов из одних социокультурных координат в другие» $[14$, с. 37]. В данном понимании перевод представляет собой трансфер художественного знания, заложенного в сюжет оригинала, являющегося проекцией реального или вымышленного мира.

При рассмотрении текста в виде модели, состоящей из четырех вышеперечисленных моделей, переводческий трансфер рассматривается в несколько ином ракурсе, под ним понимается преобразование текстовой модели оригинала, состоящей из n-числа компонентов и номинантов, в текстовую модель перевода, т. е. это реконструкция текстовой модели оригинала средствами переводного языка. В этом случае переводческий трансфер отличается от перевода тем, что при переводе проявляется «симметричная/асимметричная перекодировка единиц перевода», а при переводческом трансфере осуществляется «симметричная/асимметричная передача параметров текстовой модели».

Несмотря на то, что и при переводе, и при переводческом трансфере осуществляется достижение одной и той же цели - транскультурной коммуникации, ряд ученых считают «стирание граней между собственно переводом и другими видами межъязыкового посредничества не вполне оправданным» [15, c. 118]. Тем не менее и перевод, и переводческий трансфер нацелены на передачу смысла оригинального текста к восприятию инокультурным читателем. В свете этого значимо то, что «художественный перевод - это путь преодоления культурного изоляционизма» [16, с. 139-141]. Однако переводческий трансфер - это тоже путь преодоления проблем перекодировки культурно-маркированного сегмента текстовой модели оригинала при ее адаптации к восприятию инокультурным читателем, поскольку «the interaction of languages is always to some extent the interaction of cultures [17, p. 45] / «взаимодействие языков - всегда до некоторой степени это взаимодействие культур». Примечательно, что в данном случае существенно то, что «the construction of the interpretative models is based on linguistic and cultural knowledge» [18, p. 1103] / «интерпретативная модель основывается на лингвистическом и культурном знании».

Культурное знание - это комплексная многовекторная динамическая модель, в которой значима концептуализация различных компонентов бытия человека, в том числе и концептуализация простран- 
ства. В свете этого актуален тезис о том, что «одним из значимых направлений в исследовании процесса и результатов концептуализации пространственных параметров мира является изучение текстовой проекции концептуализации пространства как одного из форматов картины мира» [19, с. 114], поскольку «субъективное восприятие действительности накладывает отпечаток на картину мира как идеальную структуру в сознании людей» [20, с. 116].

В данной статье рассматривается текстовая художественная картина мира как один из форматов картины мира, а именно проксемная текстовая модель, состоящая, по нашему мнению, из четырех типов номинантов: 1) слова и словосочетания, семантика которых передает пространственные параметры; 2) глаголы движения; 3) топонимы; 4) пейзажные единицы как номинации пейзажа.

Переводческий трансфер проксемной текстовой модели приводит как к симметричной, так и к асимметричной адаптации номинантов проксемной модели. Под симметричной адаптацией понимается адекватная и эквивалентная передача плана содержания и плана выражения единицы перевода с исходного языка на переводной. Под асимметричной перекодировкой понимается трансформация плана содержания и/или плана выражения единицы перевода при передаче с исходного языка на переводной [21, c. 34-40]. Асимметрия номинантов интерпретируется в соответствии с концепцией языковых преобразований В. Г. Гака, в которой изложены следующие типы переводческих трансформаций: «транспозиция грамматических категорий, транспозиция частей речи, трансформация средств связи между предложениями или их частями, актантные трансформации (изменение синтаксической функции слова), лексико-семантические трансформации в слове» [22, с. 376].

Перечисленные типы преобразований номинантов проксемной текстовой модели были выявлены как результат переводческого трансфера этого типа модели, изложенной в произведении У. Черчилля «Тhe River War» и адаптированной к восприятию русскоговорящим читателем.

В исследуемой проксемной текстовой модели на основе частотности номинантов выявлены модели-доминанты и периферийные модели. В частности, к моделям-доминантам относятся следующие: проксемная текстовая модель «Египетский Судан», проксемная текстовая модель «Хартум».

\section{Проксемная текстовая модель «Египетский Судан»}

В исследуемом произведении У. Черчилля проксемная текстовая модель «Египетский Судан» представлена пятью контекстами, которые в ряде случаев пересекаются с моделью «Военный Судан», в статье не рассматриваемой. Среди выявленных контекстов проксемной текстовой модели «Египетский Судан» в статье рассмотрен следующий многокомпонентный контекст как сегмент модели:

«The north-eastern quarter of the continent of Africa is drained and watered by the Nile. Among and about the headstreams and tributaries of this mighty river lie the wide and fertile provinces of the Egyptian Soudan. Situated in the very centre of the land, these remote regions are on every side divided from the seas by five hundred miles of mountain, swamp, or desert» [23, p. 76] / «Воды Нила питают всю северо-восточную часть Африканского континента. В верховьях этой могучей реки и у ее притоков расположены обширные и плодородные провинции Египетского Судана. Находящиеся почти в самом центре континента, эти отдаленные районы со всех сторон окружены горами, болотами и пустынями, простирающимися на пятьсот миль» [24, с. 7].

В рассматриваемом сегменте проксемной текстовой модели «Египетский Судан» представлено два компонента: 1) географическое месторасположение Египетского Судана, выраженное тремя проксемными номинантами; 2) пейзаж Египетского Судана.

Сравнительно-сопоставительный анализ компонентов проксемной модели оригинального и переведенного контекстов выявил, что при адаптации первого номинанта, входящего в состав компонента «географическое месторасположение Египетского Судана», употреблена актантная трансформация взаимозамена подлежащего и второстепенного члена предложения: «The north-eastern quarter of the continent of Africa is drained and watered by the Nile» - «Воды Нила питают всю северо-восточную часть Африканского континента». Проксема «the north-eastern quarter of the continent of Africa» утратила позицию подлежащего и перешла в статус дополнения «северо-восточную часть Африканского континента», тогда как дополнение «watered by the Nile» трансформировано в подлежащее «Воды Нила», тем самым описания двух типов пейзажа в проксемной текстовой модели поменялись местами. Если в оригинале повествование начинается с указания на земной пейзаж, то в тексте перевода повествование начинается с указания на водный пейзаж. Более того, в русскоязычном контексте выявлена вставка - лексема «всю», употребленная по отношению к наименованию географического пространства «северо-восточная часть Африканского континента». В этом же номинанте определена синтаксическая транспозиция топонима «the continent of Africa», он передан как «Африканский континент», где имя существительное «Africa», создающее определенный «образ в сознании человека» [25, с. 698], переведено именем прилагательным «Африканский». Синтаксическая транспозиция не влияет на степень адаптации модели, в отличие от 
рассмотренной актантной трансформации первого номинанта, которая изменяет пространственные параметры модели.

Во втором номинанте указана более локальная точка в пространстве по сравнению с вышерассмотренным первым номинантом «Северо-Восточная часть Африканского континента», а именно «Верховья Нила» в следующей конструкции «Among and about the headstreams and tributaries of this mighty river lie the wide and fertile provinces of the Egyptian Soudan». Проксемная конструкция адаптирована средствами русского языка следующим образом: «В верховьях этой могучей реки и у ее притоков расположены обширные и плодородные провинции Египетского Судана».

Сравнительно-сопоставительный анализ проксемного номинанта на двух языках выявил лексико-семантическую замену номинанта «the headstreams» (истоки) на номинант «верховья», не влияющую на проксемную модель в целом, тогда как трансформация форм связи в предложении при адаптации проксемы «among and about the headstreams and tributaries of this mighty river» проксемой «в верховьях этой могучей реки и у ее притоков» привела к трансформации этой части рассматриваемой проксемной модели, поскольку в оригинальном контексте предстает целостная картина истоков и притоков могучей реки, тогда как в русскоязычном контексте сначала перед читателем предстает верховье (истоки) могучей реки, а затем ее притоки. Третий проксемный номинант маркирует еще более локальное пространство по сравнению со вторым номинантом: «Situated in the very centre of the land, these remote regions are on every side divided from the seas by five hundred miles of mountain, swamp, or desert».

Следовательно, изображенное в рассматриваемом контексте У. Черчиллем текстовое пространство имеет центростремительный проксемный вектор, под которым понимается последовательное описание пространства от более обширного к менее обширному. Проксема «Situated in the very centre of the land» переведена симметрично в плане содержания и в плане выражения, а именно как «находящиеся почти в самом центре континента». Вторая часть проксемного номинанта представляет собой пейзажную единицу «these remote regions are on every side divided from the seas by five hundred miles of mountain, swamp, or desert», которая перекодирована в плане содержания и в плане выражения асимметрично, поскольку в проксемном номинанте оригинального контекста говорится о том, что удаленные центральные районы континента отделены от морей пятью сотнями миль гор, т. е. У. Черчилль в тексте разделял пространство на два сегмента: 1) центр континента; 2) отделенное горами иное пространство, тогда как в переведенном сегменте проксемной модели внимание русскоязычного читателя привлекается только к центру континента: «отдаленные районы со всех сторон окружены горами, болотами и пустынями, простирающимися на пятьсот миль», поскольку проксема «divided from the seas» нивелирована. Что касается пейзажных единиц «mountain, swamp, or desert», то они адаптированы симметрично пейзажными единицами «горами, болотами и пустынями».

В целом, рассмотренный сегмент проксемной текстовой модели «Египетский Судан» трансформирован в результате переводческого трансфера из англоязычного текстового мира в русскоязычный текстовый мир. Более того, установлено, что остальные четыре контекста, детально не описанные в статье, тоже были трансформированы в результате переводческого трансфера.

\section{Проксемная текстовая модель «Хартум»}

В рассматриваемом произведении У. Черчилля Хартуму отведена значимая роль, как одному из городов Судана. Хартум упомянут во многих контекстах и описан в 17 контекстах, значительная часть из которых в той или иной степени трансформирована в процессе переводческого трансфера. Так, к примеру, в следующем контексте описанию Хартума отводится значимое место: "The town of Khartoum, at the confluence of the Blue and White Niles, is the point on which the trade of the south must inevitably converge. It is the great spout through which the merchandise collected from a wide area streams northward to the Mediterranean shore. It marks the extreme northern limit of the fertile Soudan. Between Khartoum and Assuan the river flows for twelve hundred miles through deserts of surpassing desolation»» $[23$, p. 76]. Контекст передан на русский язык следующим образом: «Хартум, расположенный у слияния Голубого и Белого Нила, представляет собой точку, из которой торговые караваны со всей страны устремляются на север к Средиземноморскому побережью. Именно здесь находится северная граница плодородных земель Судана. Далее почти тысячу двести миль между Хартумом и Асуаном река протекает по безжизненной пустыне» [24, с. 7].

В контексте ядро модели, топоним Хартум, является средоточием торговых путей со всей страны, затем эти торговые пути устремляются к Средиземному побережью. В отличие от пространственного центростремительного вектора в модели «Южный Судан» в текстовой модели «Хартум» множество пространственных векторов (торговые караваны с юга страны) сходятся в Хартуме, а затем, объединившись, устремляются на север, к Средиземному морю.

Сравнительно-сопоставительный анализ показывает, что первые два предложения оригинального контекста посредством трансформации форм связи в 
предложении адаптированы на русский язык одним предложением, в котором объединены два взаимосвязанных слова «the trade» (торговля) и «the merchandise» (торговец) в одно понятие «торговые караваны», репрезентирующее динамику перемещения в пространстве. Эта трансформация привела к тому, что отраженные в текстовой модели оригинала два динамических пространства, перемещение в которых направлено «с Юга в Хартум» и «из Хартума к Средиземному морю», объединены в одно динамическое пространство, где есть указание только одной стороны Света, т. е. сказано только о движении на север. Нивелировка лексемы «the south» также привела к искажению параметров пространственной модели оригинала, где лексемы «the south» и «northward» указывали на противоположные стороны Света, но это противопоставление нивелировано в проксемной модели текста на русском языке.

Хартум указан как точка, объединяющая два типа пространства: неперсонифицированное пространство: «The town of Khartoum, at the confluence of the Blue and White Niles» и персонифицированное пространство: «the point on which the trade of the south must inevitably converge». Сравнительно-сопоставительный анализ этого сегмента проксемной модели оригинального текста и переводного показал, что проксема, относящаяся к неперсонифицированному пространству «at the confluence of the Blue and White Niles», передана симметрично, а именно «у слияния Голубого и Белого Нила», тогда как проксема, относящаяся к персонифицированному пространству «the point on which the trade of the south must inevitably converge», указывающая на прибытие торговли в город Хартум, в тексте перевода трансформирована, поскольку говорится только об отбытии торговых караванов из точки в части предложения «из которой торговые караваны <.. > устремляются на север...».

Примечательно, что город Хартум как точка в текстовом пространстве упомянут посредством четырех проксем: 1) топонима «the town of Khartoum»; 2) проксемы, обозначающей географическое местонахождение «at the confluence of the Blue and White Niles»; 3) проксемы, обозначающей экономическое месторасположение «the point on which the trade...»; 4) проксемы, обозначающей точку на границе «It marks the extreme northern limit of the fertile Soudan».

Сопоставление перечисленных четырех проксем в оригинальной проксемной текстовой модели и переведенной показало следующее: 1) топоним «the town of Khartoum» трансформирован в плане выражения, поскольку нивелирована лексема «the town», что привело к асимметричной передаче плана содержания, поскольку читатель, не имеющий достаточно географических фоновых знаний, может не определить, что «Хартум» - это город; 2) проксема, обозна- чающая географическое местонахождение «at the confluence of the Blue and White Niles», передана симметрично в плане содержания и в плане выражения на русский язык: «у слияния Голубого и Белого Нила»; 3) проксема, обозначающая экономическое месторасположение: «the point on which (the trade)...», переведена симметрично: «представляет собой точку, из которой (торговые караваны)...»; 4) проксема, обозначающая точку на границе: «the extreme northern limit of the fertile Soudan» (крайняя северная граница плодородного Судана), перекодирована асимметрично, поскольку вследствие нивелировки лексемы «extreme» (крайняя), характеризующей местонахождение Хартума на карте Судана, читатель русскоязычного текста видит описание: «находится северная граница плодородных земель Судана», которое отличается от описания, данного У. Черчиллем.

Следующая проксемная конструкция рассматриваемого контекста указывает на часть Нила, протекающего между Хартумов и Ассуаном: «Between Khartoum and Assuan the river flows for twelve hundred miles through deserts of surpassing desolation», т. е. конструкция состоит из трех типов проксем: 1) двух топонимов: «Khartoum», «Assuan»; 2) словосочетания, семантика которого маркирует пространство: «for twelve hundred miles»; 3) пейзажной единицы «the river flows $\langle\ldots>$ through deserts of surpassing desolation».

Сравнительно-сопоставительный анализ рассматриваемой проксемной конструкции в текстовой модели оригинала и текста перевода выявил преобладание симметричного перевода двух проксем из трех, т. е.: 1) топонимы «Khartoum», «Assuan» переданы симметрично как «Хартум», «Асуан»; 2) словосочетание «for twelve hundred miles», отражающее национальную специфику учета расстояния англичан, переведено эквивалентом, в состав которого включена англоязычная лингвокультурема «miles»; 3) пейзажная единица «the river flows $<\ldots>$ through deserts of surpassing desolation» (река протекает через пустыни крайнего запустения) перекодирована асимметрично в плане содержания и выражения: «река протекает по безжизненной пустыне», поскольку в проксемном сегменте оригинальной модели упоминается несколько пустынь, т. е. пространство дробится, тогда как в модели переведенного текста сказано об одной пустыне, поэтому изображенное пейзажное пространство целостно. Более того, имя существительное «desolation» (запустение) переведено асимметрично именем прилагательным «безжизненная». Следовательно, несмотря на то, что две проксемы из трех переданы симметрично, преобразование третьей проксемы способствовало асимметрии пространственных параметров рассматриваемой текстовой модели в текстах оригинала и перевода. 
Следовательно, все перечисленные изменения этого сегмента проксемной текстовой модели, осуществленные при ее переводческом трансфере, привели к асимметричной передаче модели средствами русского языка.

\section{Заключение}

Рассмотрение текстовой сюжетно-тематической модели в виде совокупности четырех моделей, а именно культурно-маркированной текстовой модели, темпоральной текстовой модели, проксемной текстовой модели, эмотивной текстовой модели, способствовало проникновению в текстовую материю с целью всесторонней интерпретации и моделирования текстового формата знания.

Предложенное авторское преломление концепции моделирования текста в свете переводоведения создало предпосылки для изучения результатов такого явления, как переводческий трансфер, посредством которого различные типы текстовых моделей переносятся из одного лингвокультурного мира в другой лингвокультурный мир, поскольку переводческий трансфер понимается в проведенном исследовании как процесс перехода текстовой модели оригинала, состоящей из n-числа компонентов и номинантов, в текстовую модель перевода на основе явления реконструкции параметров текстовой модели оригинала средствами переводного языка.

Рассмотрение результатов переводческого трансфера ряда сегментов двух моделей-доминат «Египетский Судан» и «Хартум», входящих в проксемную модель произведения У. Черчилля «The River War» и состоящих из четырех типов номинантов: 1) слова и словосочетания, семантика которых передает пространственные параметры; 2) глаголы движения; 3) топонимы; 4) пейзажные единицы, - показало, что перечисленные номинанты-проксемы в рассмотренной части сегментов текстовой проксемной модели были преимущественно трансформированы, что привело к неполной реконструкции средствами русского языка исходных параметров, входящих в рассмотренные сегменты моделей-доминант «Египетский Судан» и «Хартум».

Исследование переводческого трансфера пространственных моделей, входящих в произведение У. Черчилля «The River War», где эти модели предстают этнокультурным фоном для описания военных событий, выявило значительную часть преобразований плана выражения проксем как единиц перевода, что позволило установить превалирование трансформации проксемных моделей оригинального англоязычного произведения при адаптации к восприятию русскоязычным читателем.

\section{ЛИТЕРАТУРА}

1. Белоусов К. И. Модельная лингвистика и проблемы моделирования языковой реальности // Вестник ОГУ. 2010. № 11 (117). С. 94-97.

2. Галло Я., Алефиренко Н. Ф. Лингвистика текста : традиции и перспективы // Филологический класс. 2020. T. 25, № 3. С. 23-38.

3. Алефиренко Н. Ф., Шахпутова 3. Х. Автохтонная синергия дискурса художественного текста // Русский язык в современном научном и образовательном пространстве : сб. тез. Междунар. науч. конф. М., 2020. С. 3-6.

4. Щирова И. А. Изучение текста как сложного образования : возможности и пределы моделирования // Когнитивные исследования языка. 2014. № 18. С. 187190.

5. McLaughlin D. The Work and the World : Mobilities and Literary Space // Literary Geographies. 2016. № 2 (2). Pp. 122-127. URL: https://doi.org/10.17863/CAM.9473

6. Koster C. Comparative approaches to translation. Handbook of translation studies / ed. by Yves Gambier, Luc van Doorslaer. Amsterdam ; Philadelphia : John Benjamins Publishing Co., 2011. Pp. 21-26.

7. Koster C. Literary Translation. Translation : A Multidisciplinary Approach, Juliane House (ed.). Hampshire, England : Palgrave MacMillan, 2014. Pp. 140-158.

8. Борисова Л. В. К вопросу о национально-культурных особенностях языкового моделирования мира // Тюркское языкознание XXI века : лексикология и лексикография : материалы Междунар. науч. конф., посвящ. 80-летию создания Института языка, литературы и искусства им. Г. Ибрагимова. Казань, 2019. С. 52-54.

9. Хвесько Т. В., Третьякова С. Ю. Когнитивно-прагматический аспект антропонимов в художественном дискурсе // Когнитивные исследования языка. 2019. T. 37. C. 562-567.

10. Scott $\mathrm{Cl}$. The work of literary translation. University of East Anglia. Padstow, Cornwall : Cambridge University Press. Printed in the United Kingdom by TJ International Ltd., 2018. 297 p.

11. Scott Cl. Translating the perception of text. Literary Translation and phenomenology. Legenda. Modern Humanities Research Association and Routledge, 2012. 194 p.

12. Чайковский P. Р. Рельефные сегменты художественного текста как переводческая задача // Вестник Волгоград. гос. ун-та. Сер. 2. Языкознание. 2017. Т. 16, № 3. C. 18-29. URL: https://doi.org/10.15688/jvolsu 2.2017.3.2

13. Комуцици Л. В., Гончарова Н. С. Языковые средства пространственно-временной референции в поэме Э. А. По «Ворон» // Дискурс. 2018. № 6 (20). С. 80-86.

14. Леонтьева К. И. Доминантный принцип перевода и механизмы его реализации в дискурсе // Вопросы когнитивной лингвистики. 2018. № 4. С. 37-46.

15. Валуйцева И. И., Хухуни Г. Д. Переводной дискурс и текст оригинала : воспроизводить или заменять? // Когнитивные исследования языка. 2019. № 36. С. 118125. 
16. Жирова И. Г., Цзякан Ч. Художественный перевод как средство преодоления культурного изоляционизма // Актуальные проблемы лингвокультурологии и межкультурной коммуникации в теории и практике перевода : материалы Всерос. науч.-практ. конф. с междунар. участием. М., 2020. С. 139-141.

17. Khukhuni G. T., Valuitseva I. I. Traslingualism/ transculturality and ethno-cultural identity : complementarity or conflictness? // Polylinguality and Transcultural Practices. 2019. T. 16, № 1. C. 45-51.

18. Ogneva E. A. et al. Interpretative model of linguacultural knowledge// The Social Sciences (Pakistan). 2015. T. 10, № 6. Pp. 1101-1106.

19. Огнева E. A. Особенности пространственной модели «Новая Атлантида» в архитектонике утопии Ф. Бэкона // Гуманитарные исследования. 2017. № 3 (63). C. $113-119$.

20. Кушнерук С. Л. Развитие теории когнитивно-дискурсивного миромоделирования за рубежом и в России // Вопросы когнитивной лингвистики. 2018. № 4. С. 115-125.

21. Моисеева C. А., Огнева E. А. Художественный текст как объект межкультурной адаптации : монография. 3-е изд., доп. М. : Эдитус, 2013. 192 с.

22. Гак В. Г. Языковые преобразования. М. : Школа «Языки русской культуры», 1998. 768 с.

23. Churchill W. S. The river war and other works. London : Kindle Edition, 2010. 1421 p. (Halcyon Classic Series).

24. Черчилль У. Индия, Судан, Южная Африка. Походы британской армии. М. : Эксмо, 2004. 560 с.

25. Хвесько Т. В. Имя в сознании человека // Когнитивные исследования языка. 2016. № 24. С. 696-704.

\section{REFERENCES}

1. Belousov K. I. Model'naja lingvistika i problemy modelirovanija jazykovoj real'nosti [Model linguistics and issues of modeling language reality]. In: Vestnik OGU. 2010. No. 11 (117). Pp. 94-97.

2. Gallo Ja., Alefirenko N. F. Lingvistika teksta: tradicii i perspektivy [Linguistics of the text: traditions and perspectives]. In: Filologicheskij klass. 2020. T. 25, No. 3. Pp. 23-38.

3. Alefirenko N. F., Shahputova Z. H. Avtohtonnaja sinergija diskursa hudozhestvennogo teksta [Autochthonous synergy of the discourse of a literary text]. In: Russkij jazyk $v$ sovremennom nauchnom i obrazovatel'nom prostranstve: sb. tezisov Mezhdunarodnoj nauchnoj konferencii, posvjashhennoj 90-letiju prof. S. A. Havroninoj. M., 2020. Pp. 3-6.

4. Shhirova I. A. Izuchenie teksta kak slozhnogo obrazovanija: vozmozhnosti i predely modelirovanija [The study of the text as a complex construction: the possibilities and limits of modeling]. In: Kognitivnye issledovanija jazyka. 2014. No. 18. Pp. 187-190.

5. McLaughlin D. The Work and the World: Mobilities and Literary Space. In: Literary Geographies. 2016. No. 2(2). Pp. 122-127. Available at: https://doi.org/10.17863/ CAM.9473 (acceded 02/02/2021).
6. Koster C. Comparative approaches to translation. Handbook of translation studies. Ed. by Yves Gambier, Luc van Doorslaer. Amsterdam; Philadelphia : John Benjamins Publishing Co., 2011. Pp. 21-26.

7. Koster C. Literary Translation. Translation: A Multidisciplinary Approach. Juliane House (ed.). Hampshire, England: Palgrave MacMillan, 2014. Pp. 140-158.

8. Borisova L. V. K voprosu o nacional'no-kul'turnyh osobennostjah jazykovogo modelirovanija mir [About national and cultural features of language modeling world]. In: Tjurkskoe jazykoznanie XXI veka: leksikologija i leksikografija: Materialy mezhdunarodnoj nauchnoj konferencii, posvjashh. 80-letiju sozdanija Instituta jazyka, literatury $i$ iskusstva im. G. Ibragimova. Kazan, 2019. Pp. 52-54.

9. Hves'ko T. V., Tret'jakova S. Ju. Kognitivno-pragmaticheskij aspekt antroponimov v hudozhestvennom diskurse [Cognitive-practical aspect of anthroponyms in literary discourse]. In: Kognitivnye issledovanija jazyka. 2019. T. 37. Pp. 562-567.

10. Scott Cl. The work of literary translation. University of East Anglia. Padstow, Cornwall : Cambridge University Press. Printed in the United Kingdom by TJ International Ltd., 2018. 297 p.

11. Scott Cl. Translating the perception of text. Literary Translation and phenomenology. Legenda. Modern Humanities Research Association and Routledge, 2012. 194 p.

12. Chajkovskij R. R. Rel'efnye segmenty hudozhestvennogo teksta kak perevodcheskaja zadacha [Relief segments of literary text as a translation task]. In: Vestnik Volgogradskogo gosudarstvennogo universiteta. Serija 2, Jazykoznanie. 2017. T. 16, No. 3. Pp. 18-29. Available at: https://doi.org/10.15688/jvolsu2.2017.3.2

13. Komucci L. V., Goncharova N. S. Jazykovye sredstva prostranstvenno-vremennoj referencii v pojeme Je. A. Po «Voron» [Linguistic means of space-time reference in the poem by E. A. Po "Raven"]. In: Diskurs. 2018. No. 6 (20). Pp. 80-86.

14. Leont'eva K. I. Dominantnyj princip perevoda $i$ mehanizmy ego realizacii $v$ diskurse [The dominant principle of translation and the mechanisms for its implementation in discourse]. In: Voprosy kognitivnoj lingvistiki. 2018. No. 4. Pp. 37-46.

15. Valujceva I. I., Huhuni G. T. Perevodnoj diskurs $i$ tekst originala: vosproizvodit' ili zamenjat'? [Translated discourse and the original text: to reproduce or replace ?]. In: Kognitivnye issledovanija jazyka. 2019. No. 36. Pp. 118-125.

16. Zhirova I. G., Czjakan Ch. Hudozhestvennyj perevod kak sredstvo preodolenija kul'turnogo izoljacionizma [Literary translation as a means of overcoming cultural isolationism]. In: Aktual'nye problemy lingvokul'turologii i mezhkul'turnoj kommunikacii v teorii i praktike perevoda: materialy Vserossijskoj nauchno-prakticheskoj konferencii s mezhdunarodnym uchastiem. Moskow, 2020. Pp. 139-141.

17. Khukhuni G. T., Valuitseva I. I. Traslingualism/ transculturality and ethno-cultural identity: complementarity or conflictness? In: Polylinguality and Transcultural Practices. 2019. T. 16, No. 1. Pp. 45-51. 
18. Ogneva E. A., Danilenko I. A., Kireeva Y. I., Kutsenko A. A. Interpretative model of linguacultural knowledge. In: The Social Sciences (Pakistan). 2015. T. 10, No. 6. Pp. 1101-1106.

19. Ogneva E. A. Osobennosti prostranstvennoj modeli «Novaja Atlantida»v arhitektoniki utopii F. Bekona [Features of the spatial model "New Atlantis" in the architectonics of the utopia of F. Bacon]. In: Gumanitarnye issledovanija. 2017. No. 3 (63). Pp. 113-119.

20. Kushneruk S. L. Razvitie teorii kognitivno-diskursivnogo miromodelirovanija za rubezhom iv Rossii [Development of the theory of cognitive-discursive world modeling abroad and in Russia]. In: Voprosy kognitivnoj lingvistiki. 2018. No. 4. Pp. 115-125.

Белгородский государственный национальный исследовательский университет

Огнева Е. А., доктор филологических наук, доиент, заведующая кафедрой иностранных языков

E-mail:ogneva@bsu.edu.ru

Поступила в редакцию 29 марта 2021 г.

Принята к публикачии 15 октября 2021 г.

\section{Для цитирования:}

Огнева $E$. А. Переводческий трансфер проксемной текстовой модели (на материале произведения У. Черчилля «The River War») // Вестник Воронежского государственного университета. Серия: Лингвистика и межкультурная коммуникация. 2021. № 4. С. 96-104. DOI: https://doi.org/10.17308/lic.2021.4/3816
21. Moisseeva S. A., Ogneva E. A. Hudozhestvennyj tekst kak ob'ekt mezhkul'turnoj adaptacii [Literary text as the object of crosscultural adaptation]. M.: Editus, 2013. 92 p.

22. Gak V. G. Jazykovye preobrazovanija [Language transformations]. M.: Shkola "Jazyki russkoj kul'tury", 1998. $768 \mathrm{p}$.

23. Churchill W. S. The river war and other works. London : Kindle Edition. 2010. 1421 p. (Halcyon Classic Series.)

24. Cherchill' U. Indija, Sudan, Juzhnaja Afrika. Pohody britanskoj armii [India, Sudan, South Africa. Campaigns of the British Army]. M. : Jeksmo, 2004. 560 p.

25. Hves'ko T. V. Imja v soznanii cheloveka [Name in human consciousness]. Kognitivnye issledovanija jazyka. 2016. No. 24. Pp. 696-704.

Belgorod State National Research University

Ogneva E. A., Doctor of Philology, Associate Professor, Head of the Foreign Languages Department

E-mail:ogneva@bsu.edu.ru

Received: 29 March 2021

Accepted: 15 October 2021

\section{For citation:}

Ogneva E. A. Translation transfer of proxemic text model in W. Churchill's "The River War". Proceedings of Voronezh State University. Series: Linguistics and Intercultural Communication. 2021. No. 4. Pp. 96-104. DOI: https:// doi.org/10.17308/lic.2021.4/3816 